\title{
Erratum to: Isolation and characterization of 14 polymorphic microsatellite DNA loci for the endangered Whooping Crane (Grus americana) and their applicability to other crane species
}

\author{
Kenneth L. Jones • Jessica R. Henkel · \\ Jerome J. Howard $\cdot$ Stacey L. Lance $\cdot$ \\ Chris Hagen • Travis C. Glenn
}

Published online: 11 June 2010

(C) Springer Science+Business Media B.V. 2010

Erratum to: Conservation Genet Resour

DOI 10.1007/s12686-010-9196-3

Sequences for loci 24 and 25 are incorrect. The following primer sequences are the correct ones for Table 1.

GRAM24 CAGTCGGGCGTCATCAGCAAAGAGGAGGGAAGAATG

TGAACATAGCAAGATCGTGGAG

GRAM25 CAGTCGGGCGTCATCACCTCACATGAAAGCCACTCAAAG

AAGGGACGCTGTCTGCTTAGG

The online version of the original article can be found under doi: 10.1007/s12686-010-9196-3.

K. L. Jones $(\bowtie) \cdot$ T. C. Glenn

Georgia Genomics Facility and the Department of

Environmental Health Science, University of Georgia,

Riverbend North, Room 129, 110 Riverbend Rd., Athens,

GA 30602, USA

e-mail: KenJones@uga.edu

J. R. Henkel

Department of Ecology and Evolutionary Biology,

Tulane University, New Orleans, LA 70118, USA

J. R. Henkel · J. J. Howard

Department of Biological Sciences, University of New Orleans,

New Orleans, LA 70148, USA

K. L. Jones · S. L. Lance · C. Hagen - T. C. Glenn

Savannah River Ecology Laboratory, University of Georgia,

Drawer E, Aiken, SC 29802, USA 